\title{
Prediction of Solidification Paths in Al-Si-Fe Ternary System and Experimental Verification: Part I. Fe-Containing Hypoeutectic Al-Si Alloys
}

\author{
Sanghwan Lee, Bonghwan Kim and Sangmok Lee \\ Liquid Processing \& Casting Technology R\&D Group, Korea Institute of Industrial Technology, \\ 7-47 Songdo-Dong, Yeonsu-Gu, Incheon 406-840, Korea
}

\begin{abstract}
The effects of $\mathrm{Fe}$ content and cooling rate on the solidification path and formation behavior of the $\mathrm{Al}_{5} \mathrm{FeSi}(\beta)$ phase in $\mathrm{Fe}$-containing hypoeutectic Al-Si alloys were studied based on thermodynamic analysis and pertinent experiments. The thermodynamic calculations were performed using the Thermo-Calc program. For analyses in the high alloy region of the Al-Si-Fe ternary system, a thermodynamic database for Thermo-Calc was correctly updated and revised by the collected up-to-date references. For thermodynamics-based predictions of the solidification path in Fe-containing hypoeutectic Al-Si alloys, liquidus projection (including various invariant, monovariant, and bivariant reactions and isotherms) and equilibrium phase fraction were calculated as functions of composition and temperature in the $\mathrm{Al}-\mathrm{Si}$-Fe ternary system. The calculated results were compared to experimental results using various casting runs. In order to analyze the solidification path as a function of Fe content, two representative hypoeutectic Al-Si alloys with different Fe levels were designed. To better understand the influence of cooling rate on the formation behavior of the $\beta$ phase, the two alloys were solidified under slowly- and rapidly-cooled conditions, respectively. The cooling curves of the solidified alloys were recorded by thermal analysis and various important solidification events were detected using the first derivative of the cooling curves. Microstructures of the casting samples were studied by combined analyses of optical microscopy (OM) and scanning electron microscopy (SEM). For the slowly-cooled condition with the high $\mathrm{Fe}$ level, the primary $\beta$ phase enveloping the $\mathrm{Al}_{8} \mathrm{Fe}_{2} \mathrm{Si}_{(}(\alpha)$ phase was mainly formed by the quasi-peritectic reaction of $\mathrm{L}+\alpha \rightarrow(\mathrm{Al})+\beta\left(612^{\circ} \mathrm{C}\right)$. For the rapidly-cooled condition with the high $\mathrm{Fe}$ level, the primary $\beta$ phase with morphology of a curved needle was mainly formed by the reaction of $\mathrm{L} \rightarrow(\mathrm{Al})+\beta\left(579 \sim 612^{\circ} \mathrm{C}\right)$. [doi:10.2320/matertrans.M2010422]
\end{abstract}

(Received December 13, 2010; Accepted February 17, 2011; Published April 20, 2011)

Keywords: hypoeutectic aluminum-silicon alloys, casting, solidification path, intermetallic compound, iron content, cooling rate

\section{Introduction}

Al-Si alloys, which are mostly used in the automotive industry, are highly attractive materials due to their desirable properties such as high strength to weight ratio, melt fluidity, castability, and wear resistance. ${ }^{1-5)}$ However, excessive amounts of $\mathrm{Fe}$ in Al-Si alloys usually cause industry problems such as mechanical property degradation. Given that the solubility of $\mathrm{Fe}$ in liquid $\mathrm{Al}$ alloys is considerably high, it is understandable that this leads to the dissolution of $\mathrm{Fe}$ in the steel casting tools (e.g., ladles, degassing tubes and stirring lances) during the casting process. ${ }^{6}$ ) Furthermore, during the recycling of $\mathrm{Al}-\mathrm{Si}$ ingots, $\mathrm{Fe}$-contaminated scrap is often incorporated, generally increasing the Fe content to a level of $0.4 \sim 0.8$ mass $\%{ }^{7)}$ On the other hand, the solubility of $\mathrm{Fe}$ in solid Al-Si alloys is very low, leading to the formation of various $\mathrm{Fe}$-rich intermetallic phases such as $\mathrm{Al}_{3} \mathrm{Fe}(\theta)$, $\mathrm{Al}_{8} \mathrm{Fe}_{2} \mathrm{Si}(\alpha)$, and $\mathrm{Al}_{5} \mathrm{FeSi}(\beta){ }^{8,9)}$ In particular, the needleshaped $\beta$ phase has been regarded as the most harmful phase, causing casting defects (e.g., shrinkage porosity) and degrading mechanical properties (e.g., tensile elongation, fracture toughness, fatigue resistance, and wear resistance) ${ }^{6,10-15)}$ Meanwhile, it has been also noted that excessive $\mathrm{Fe}$ content above the Fe level of the Al-Si-Fe eutectic composition prevents dissolution of $\mathrm{Fe}$ from die materials when the latter are in intimate contact with $\mathrm{Al}$ melts. For this reason, the intentional addition of $0.7 \sim 1.3$ mass $\% \mathrm{Fe}$ is occasionally practiced to prevent die soldering and hence prolong die life in the $\mathrm{Al}$ casting industry. ${ }^{15-18)}$

The first comprehensive study on the phase equilibria of the Al-Si-Fe ternary system was systematically performed using thermal analysis and microstructural examination by
Takeda and Mutuzaki. ${ }^{19)}$ Microstructural investigation of various binary and ternary intermetallic compounds of the Al-Si-Fe ternary system was extensively carried out by Gupta and Maitra using ternary diffusion couple experiments. $^{20,21)}$ More recently, experimental data for establishing the accurate phase equilibria of the ternary system were presented by Bosselet and Pontevichi ${ }^{22-25)}$ and Krendelsberger et al. ${ }^{26)}$ Precise thermodynamic datasets of the ternary system were reasonably assessed by Liu and Du. ${ }^{27,28)}$

According to Du et al. ${ }^{28)}$ the Al-Si-Fe ternary system is an extremely complex one with twenty seven ternary invariant reactions involving eleven stable ternary intermetallic compounds and a number of binary phases. Although many studies have continued to be performed, it is still tremendously difficult to predict the solidification path of high Fe-containing Al-Si alloys because of metastability, incomplete reactions, and solid-state reactions that are not well understood. Furthermore, there has been little interest in studying the formation reactions of various phases in high Fe-containing Al-Si alloys. Nevertheless, the demand has increased for fundamental knowledge on recycling $\mathrm{Fe}$ contaminated Al-Si casting alloys. The main purposes of the present study are to predict the solidification path and $\beta$ phase formation based on thermodynamic analysis and to verify the predicted results experimentally.

\section{Theoretical Prediction}

The process shown in Fig. 1 was performed to predict various solidification sequences including the formation reaction of $\beta$ phase in Fe-containing Al-Si alloys. Thermo- 


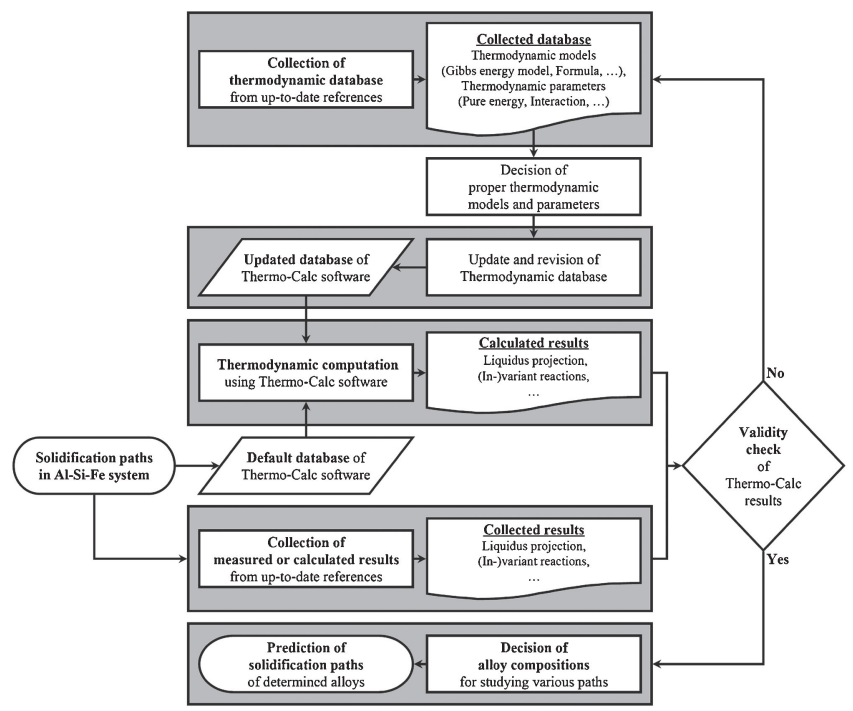

Fig. 1 Flowchart for predicting solidification paths based on thermodynamic analysis.

dynamic calculations in the Al-Si-Fe ternary system were carried out using Thermo-Calc. For the thermodynamicsbased prediction of various solidification paths in $\mathrm{Fe}$ containing hypoeutectic Al-Si alloys, the liquidus projection (including various invariant, monovariant, and bivariant reactions and isotherms) was calculated in the $\mathrm{Al}-\mathrm{Si}-\mathrm{Fe}$ ternary system.

Figure 2(a) shows the liquidus projection calculated by the unmodified default database of Thermo-Calc. Comparing this liquidus projection to that obtained from collected up-to-date references ${ }^{26-28)}$ to check the validity of the Thermo-Calc result, there was a considerable disagreement between the calculated and the collected results, especially in the region of high $\mathrm{Fe}$ alloys. In order to construct a thermodynamic database for precise calculated results, thermodynamic models (e.g., Gibbs free energy model and formula) and parameters (e.g., Gibbs free energy for pure standard state $\left({ }^{\circ} \mathrm{G}\right)$ and interaction parameter $\left.(\mathrm{L})\right)$ were collected from the up-to-date references, ${ }^{27-31)}$ and proper thermodynamic data sets were carefully determined by evaluating the quality of the experimental and calculated thermodynamic results. The recalculated liquidus projection using the correctly updated database is shown in Fig. 2(b). The newly calculated results were in consonance with the collected results from up-to-date references. Through these series of efforts, the updated database was adopted in the present thermodynamic analyses.

After predicting the solidification paths from which various formation behaviors of the $\beta$ phase could be representatively presumed, two alloy compositions with different Fe levels were selected for the hypoeutectic Al-Si alloys. The solidification paths of the selected alloys were predicted with the assumption of equilibrium solidification under the condition of complete diffusion and redistribution of all solute atoms.

\section{Experimental Procedure}

Two hypoeutectic Al-Si alloys, with much the same $\mathrm{Si}$ level (7 mass \%) but different Fe levels, were prepared from high purity Al (99.8 mass \%), Al-15 mass $\%$ Si, and Al-75 mass $\% \mathrm{Fe}$ master alloys. The raw materials were melted in a graphite crucible using an electrical resistance furnace. The melt was held at a temperature of $900^{\circ} \mathrm{C}$ for $10 \mathrm{~min}$ to stabilize and achieve complete mixing of the constituent elements. The conditioned molten materials were poured into a preheated Y-block permanent mold with a $3 \mathrm{~kg}$ cavity. The actual chemical compositions of the two cast alloys were analyzed by spark emission spectroscopy (SES, OBLF QSN750), the results of which are summarized in Table 1.

Investigations of both slow and rapid solidifications were carried out by remelting the solidified ingot after cutting to
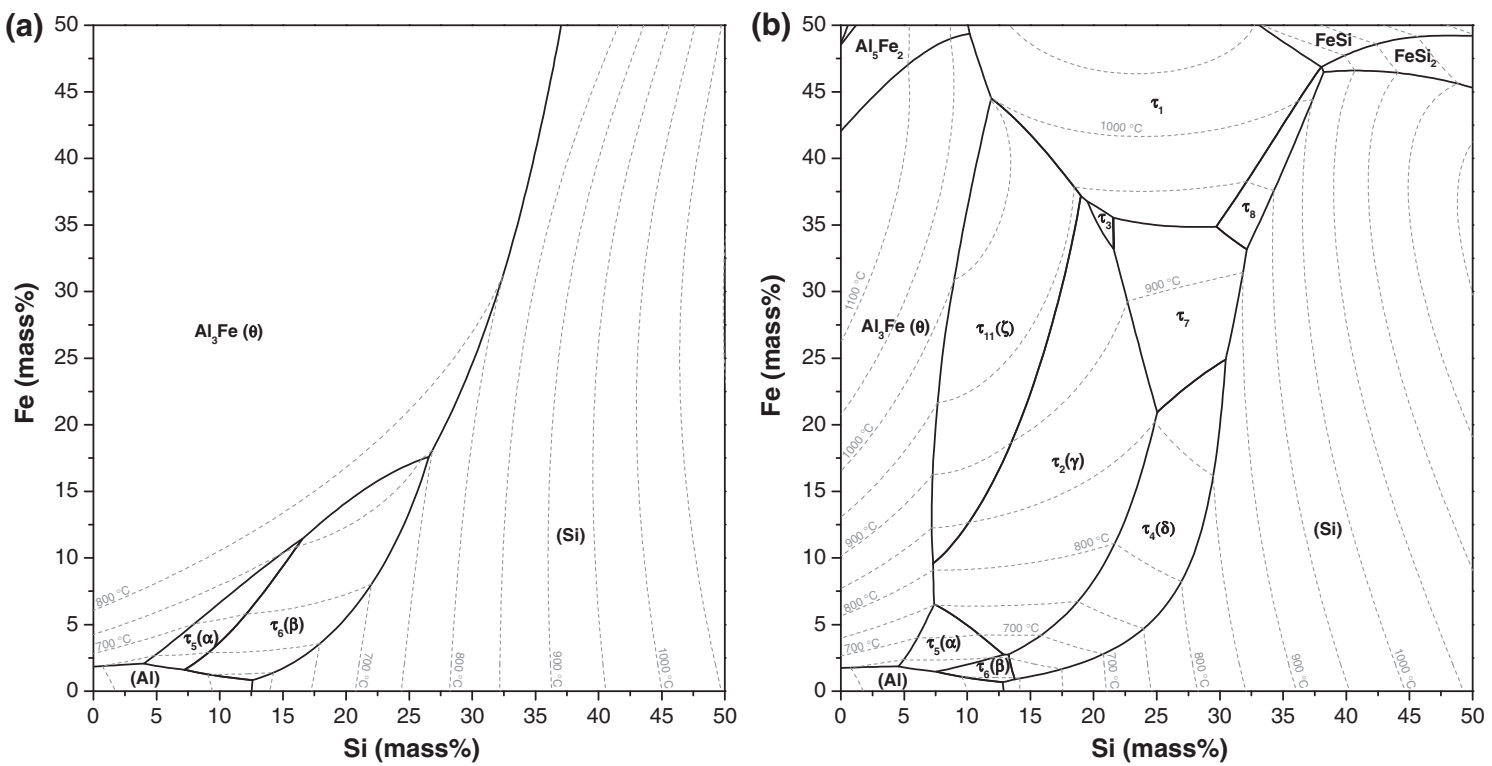

Fig. 2 Liquidus projections of the Al-Si-Fe ternary system calculated by (a) existing default database and (b) correctly updated database of Thermo-Calc. 
Table 1 Nominal and actual chemical compositions of the casting alloys.

\begin{tabular}{lccccc}
\hline \multirow{2}{*}{ Specimen } & \multicolumn{4}{c}{ Chemical composition (mass\%) } \\
\cline { 3 - 6 } & & $\mathrm{Si}$ & $\mathrm{Fe}$ & Other & $\mathrm{Al}$ \\
\hline \multirow{2}{*}{ Alloy 1} & Nominal & 7.00 & 0.20 & - & Bal. \\
& Actual & 7.25 & 0.23 & 0.03 & Bal. \\
\hline \multirow{2}{*}{ Alloy 2 } & Nominal & 7.00 & 10.00 & - & Bal. \\
& Actual & 6.97 & 10.64 & 0.14 & Bal. \\
\hline
\end{tabular}

Table 2 Symbols, chemical composition ranges, and formation temperature ranges of various ternary intermetallic compounds reported to form in the Al-rich corner of the Al-Si-Fe system.

\begin{tabular}{ccccc}
\hline \multirow{2}{*}{ Symbol } & \multicolumn{3}{c}{ Chemical composition $($ mole $\%)$} & Formation temperature, $\mathrm{T} /{ }^{\circ} \mathrm{C}$ \\
\cline { 2 - 5 } & $\mathrm{Al}$ & $\mathrm{Fe}$ & $\mathrm{Si}$ & Experiment $^{26)}$ \\
\hline$\alpha^{32)}$ & $68.0 \sim 72.0$ & $18.0 \sim 19.5$ & $10.0 \sim 12.5$ & $<766$ \\
$\beta^{32)}$ & $64.5 \sim 67.5$ & $15.5 \sim 16.5$ & $17.0 \sim 19.0$ & $<665$ \\
$\delta^{33)}$ & $45.5 \sim 54.0$ & $15.5 \sim 16.5$ & $30.5 \sim 38.0$ & $<875$ \\
$\gamma^{34)}$ & $53.9 \sim 65.3$ & $19.5 \sim 20.5$ & $15.2 \sim 25.6$ & $<900 \sim 934$ \\
$\zeta^{33)}$ & $64.0 \sim 66.5$ & $24.0 \sim 25.0$ & $9.5 \sim 11.0$ & $<997$ \\
\hline
\end{tabular}

proper size. For the investigation of slow solidification by furnace cooling, experimental verification was performed for the solidification path predicted by the thermodynamic analysis. For the investigation of rapid solidification by ice water quenching, the effect of cooling rate on the formation behavior of $\beta$ phase was examined.

The cooling curves of both solidification regimes were recorded by thermal analysis, and important solidification events were evaluated based on the first derivative of the cooling curves. The range of measured cooling rates for the slow and rapid solidifications were about $0.05 \sim 0.1$ and $250 \sim 300^{\circ} \mathrm{C} / \mathrm{s}$, respectively. Microstructural observations were carried out using optical microscopy (OM, Nikon Epiphot-200) and scanning electron microscopy (SEM, FEI Quanta-200F). The various intermetallic compounds referred to in this study were identified by the combined use of backscattered electron (BSE) imaging mode and energy dispersive X-ray spectroscopy (EDS, EDAX Apollo SDD series) of SEM.

\section{Results}

\subsection{Solidification Path}

The symbols and compositional/temperature ranges of various ternary intermetallic compounds, which have been reported to form in the Al-rich corner of the Al-Si-Fe system, are summarized in Table 2 based on several references. The various invariant and monovariant reactions that can occur in the Al-rich corner of the Al-Si-Fe system and their calculated reaction temperatures are indicated in Table 3. The solidification paths of two hypoeutectic Al-Si alloys with different Fe levels were predicted by assuming that solidification occurs under full equilibrium conditions. The predicted solidification paths of the two alloys are superimposed on the calculated liquidus projection of Fig. 3. As a summary of solidification behaviors, the predicted reaction sequences of
Table 3 Invariant and monovariant reactions in the Al-rich corner of the Al-Si-Fe system.

\begin{tabular}{ccccc}
\hline $\begin{array}{c}\text { Invariant } \\
\text { reaction } \\
\text { (point) }\end{array}$ & $\begin{array}{c}\text { Monovariant } \\
\text { reaction } \\
\text { (line) }\end{array}$ & Reaction equation & Reaction temperature, $T /{ }^{\circ} \mathrm{C}$ \\
\cline { 4 - 5 } & - & $\mathrm{L}+\theta+\gamma \rightarrow \alpha$ & Experiment ${ }^{26)}$ & Calculation \\
\hline $\mathrm{P}_{1}$ & - & $\mathrm{L}+\gamma+\delta \rightarrow \beta$ & 665 & 751 \\
$\mathrm{P}_{2}$ & - & $\mathrm{L}+\gamma \rightarrow \alpha+\beta$ & 648 & 656 \\
$\mathrm{U}_{1}$ & - & $\mathrm{L}+\theta \rightarrow(\mathrm{Al})+\alpha$ & 636 & 656 \\
$\mathrm{U}_{2}$ & - & $\mathrm{L}+\alpha \rightarrow(\mathrm{Al})+\beta$ & 609 & 628 \\
$\mathrm{U}_{3}$ & - & $\mathrm{L}+\delta \rightarrow(\mathrm{Si})+\beta$ & 596 & 612 \\
$\mathrm{U}_{4}$ & - & $\mathrm{L} \rightarrow(\mathrm{Al})+(\mathrm{Si})+\beta$ & 576 & 594 \\
$\mathrm{E}_{1}$ & - & $\mathrm{L} \rightarrow \gamma+\alpha$ & $648 \sim 766$ & $656 \sim 751$ \\
\hline- & $\mathrm{P}_{1}-\mathrm{U}_{1}$ & $\mathrm{~L} \rightarrow \theta+\alpha$ & $636 \sim 766$ & $628 \sim 751$ \\
- & $\mathrm{P}_{1}-\mathrm{U}_{2}$ & $\mathrm{~L} \rightarrow \gamma+\beta$ & $648 \sim 665$ & $656 \sim 656$ \\
- & $\mathrm{P}_{2}-\mathrm{U}_{1}$ & $\mathrm{~L} \rightarrow \delta+\beta$ & $596 \sim 665$ & $594 \sim 656$ \\
- & $\mathrm{P}_{2}-\mathrm{U}_{4}$ & $\mathrm{~L} \rightarrow \alpha+\beta$ & $609 \sim 648$ & $612 \sim 656$ \\
- & $\mathrm{U}_{1}-\mathrm{U}_{3}$ & $\mathrm{~L} \rightarrow(\mathrm{Al})+\alpha$ & $609 \sim 636$ & $612 \sim 628$ \\
- & $\mathrm{U}_{2}-\mathrm{U}_{3}$ & $\mathrm{~L} \rightarrow(\mathrm{Al})+\beta$ & $576 \sim 609$ & $579 \sim 612$ \\
- & $\mathrm{U}_{3}-\mathrm{E}_{1}$ & $\mathrm{~L} \rightarrow \beta$ & $576 \sim 596$ & $579 \sim 594$ \\
\hline & $\mathrm{U}_{4}-\mathrm{E}_{1}$ & $\mathrm{~L} \rightarrow(\mathrm{Si})+\beta$ & \\
\hline
\end{tabular}

$\mathrm{P}=$ peritectic, $\mathrm{U}=$ quasi-peritectic, and $\mathrm{E}=$ eutectic.

the two alloys and the corresponding calculated changes in liquid composition are indicated in Fig. 4. For alloy 1, the first solid phase $(\mathrm{Al})$ begins to crystallize at $617^{\circ} \mathrm{C}$, as shown in Fig. 4(a). With a temperature drop, the primary ( $\mathrm{Al}$ ) phase continues to form and the liquid composition moves to the monovariant reaction line of $\mathrm{L} \rightarrow(\mathrm{Al})+(\mathrm{Si})$ along the bivariant reaction surface of $\mathrm{L} \rightarrow(\mathrm{Al})$ because of the decrease of $\mathrm{Al}$ content in the liquid, as plotted in Fig. 3(a). After the liquid composition reaches the monovariant reaction line of $\mathrm{L} \rightarrow(\mathrm{Al})+(\mathrm{Si})$, the eutectic $(\mathrm{Al})$ and $(\mathrm{Si})$ phases crystallize and the liquid composition moves to the eutectic reaction point $\mathrm{E}_{1}$ of $\mathrm{L} \rightarrow(\mathrm{Al})+(\mathrm{Si})+\beta\left(579^{\circ} \mathrm{C}\right)$. After the liquid composition reaches point $\mathrm{E}_{1}$, the eutectic (Al), ( $\mathrm{Si}$ ), and $\beta$ phases crystallize until all of the liquid is exhausted.

For alloy 2, the first solid phase $\theta$ begins to crystallize at $825^{\circ} \mathrm{C}$, as shown in Fig. 4(b). As the temperature drops, the primary $\theta$ phase continues to precipitate out of the liquid; the liquid composition moves to the monovariant reaction line of $\mathrm{L} \rightarrow \theta+\gamma$ along the bivariant reaction surface of $\mathrm{L} \rightarrow \theta$, as plotted in Fig. 3(b). As the temperature drops further, the $\theta$ and $\gamma$ phases crystallize and liquid composition moves to the peritectic reaction point $\mathrm{P}_{1}$ of $\mathrm{L}+\theta+\gamma \rightarrow \alpha\left(751^{\circ} \mathrm{C}\right)$ along the monovariant reaction line of $\mathrm{L} \rightarrow \theta+\gamma$. At point $\mathrm{P}_{1}$, the primary $\alpha$ phase begins to crystallize. As both $\theta$ and $\alpha$ phases crystallize, the liquid composition moves to the quasiperitectic reaction point $\mathrm{U}_{2}$ of $\mathrm{L}+\theta \rightarrow(\mathrm{Al})+\alpha\left(628^{\circ} \mathrm{C}\right)$ along the monovariant reaction line $\mathrm{P}_{1}-\mathrm{U}_{2}$ of $\mathrm{L} \rightarrow \theta+\alpha$ $\left(628 \sim 751^{\circ} \mathrm{C}\right)$ because of the decrease of $\mathrm{Si}$ and $\mathrm{Fe}$ in the liquid. At point $\mathrm{U}_{2}$, the primary (Al) phase begins to crystallize. As both (Al) and $\alpha$ phases crystallize, the liquid composition moves to the quasi-peritectic reaction point $\mathrm{U}_{3}$ of $\mathrm{L}+\alpha \rightarrow(\mathrm{Al})+\beta\left(612^{\circ} \mathrm{C}\right)$ along the monovariant reaction line $\mathrm{U}_{2}-\mathrm{U}_{3}$ of $\mathrm{L} \rightarrow(\mathrm{Al})+\alpha\left(612 \sim 628^{\circ} \mathrm{C}\right)$. At point $\mathrm{U}_{3}$, the primary $\beta$ phase begins to crystallize. The formations of the $(\mathrm{Al})$ and $\beta$ phases continue until the liquid 

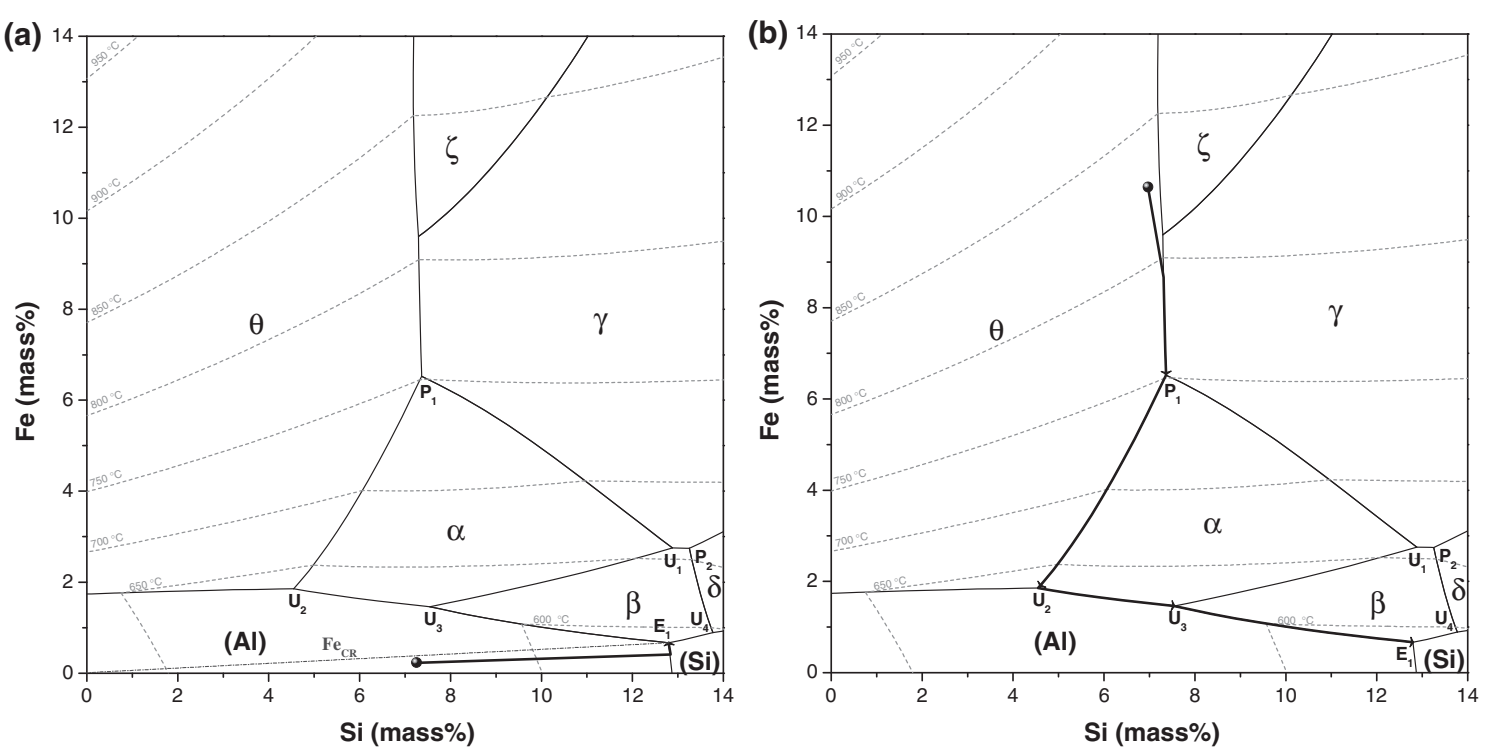

Fig. 3 Calculated liquidus projection and isotherms in the Al-rich corner of the Al-Si-Fe system and the predicted equilibrium solidification paths; (a) alloy 1 and (b) alloy 2.
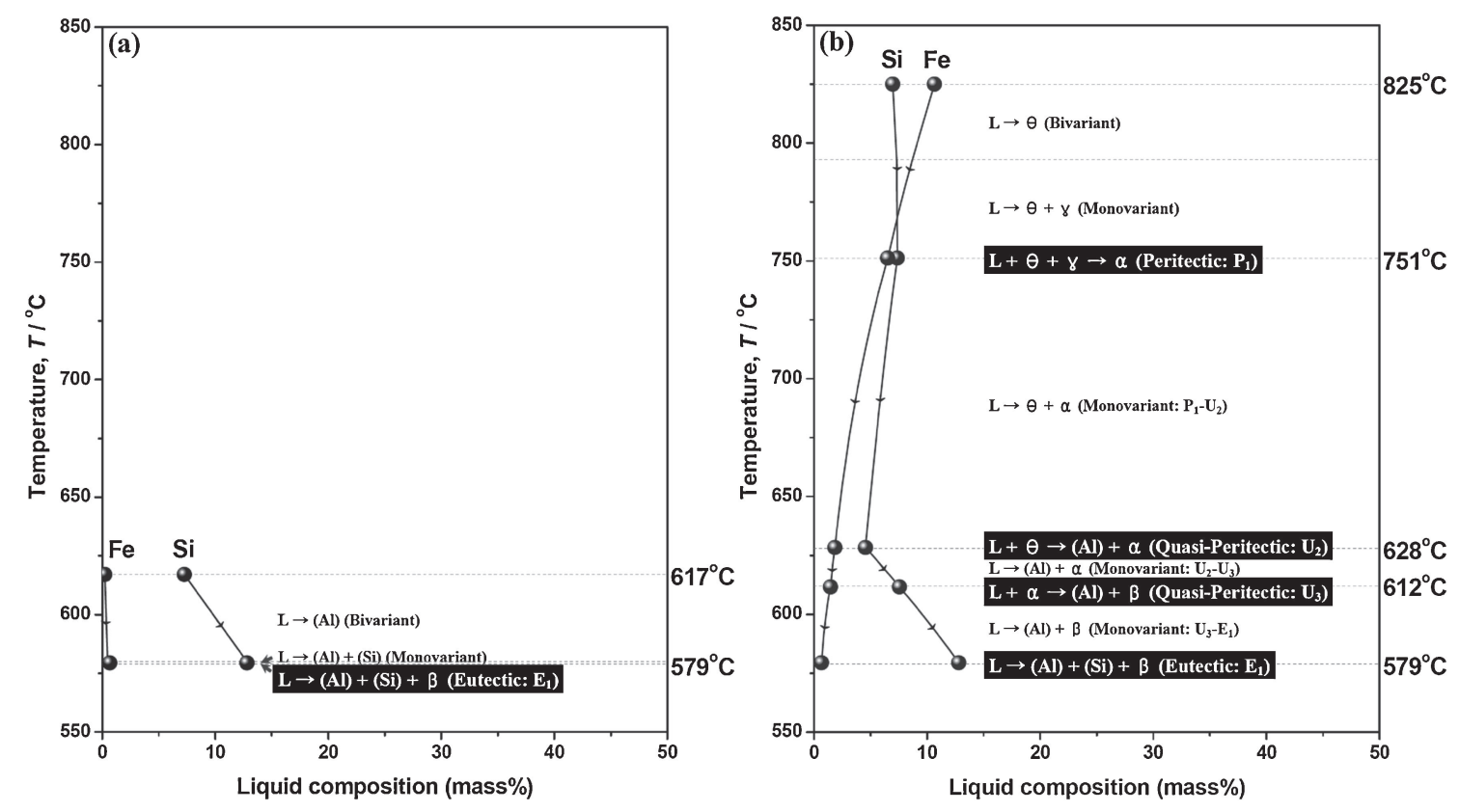

Fig. 4 Reaction sequences predicted under the assumption of equilibrium solidification and corresponding changes in liquid composition; (a) alloy 1 and (b) alloy 2 .

composition reaches point $\mathrm{E}_{1}$ along the monovariant reaction line $\mathrm{U}_{3}-\mathrm{E}_{1}$ of $\mathrm{L} \rightarrow(\mathrm{Al})+\beta\left(579 \sim 612^{\circ} \mathrm{C}\right)$. Finally, the eutectic $\beta$ phase, as in alloy 1 , is formed together with the $(\mathrm{Al})$ and $(\mathrm{Si})$ phases by the ternary eutectic reaction $\mathrm{E}_{1}$ until all of the liquid is exhausted.

\subsection{Microstructure}

The formation characteristics of the intermetallic compounds observed in four specimens of low and high $\mathrm{Fe}$ containing hypoeutectic Al-Si alloys solidified under slowlyand rapidly-cooled conditions are summarized in Table 4. The chemical compositions of various intermetallic compounds measured by EDS are indicated in Table 5. The representative microstructures of the slowly-cooled low Fecontaining hypoeutectic Al-Si alloy are shown in Fig. 5. For the slowly-cooled alloy 1 , the microstructure consists of a dendritic primary (Al) phase together with eutectic (Al) and (Si) phases of lamellar structure, as shown in Fig. 5(a). A small amount of needle-shaped eutectic $\beta$ phase was observed in Fig. 5(b). As is clearly shown in Fig. 5(c), the eutectic $\beta$ phase is the only intermetallic compound found in the microstructure of alloy 1 , being observed in the interdendritic regions. The lengths of the eutectic $\beta$ phase needles range from $10 \sim 100 \mu \mathrm{m}$, as shown in Fig. 5(d).

Figure 6 shows the representative microstructures of the slowly-cooled high Fe-containing hypoeutectic Al-Si alloy. 
Table 4 Formation characteristics of intermetallic compounds observed in four different specimens of low and high Fe-containing hypoeutectic Al-Si alloys solidified under slowly- and rapidly-cooled conditions.

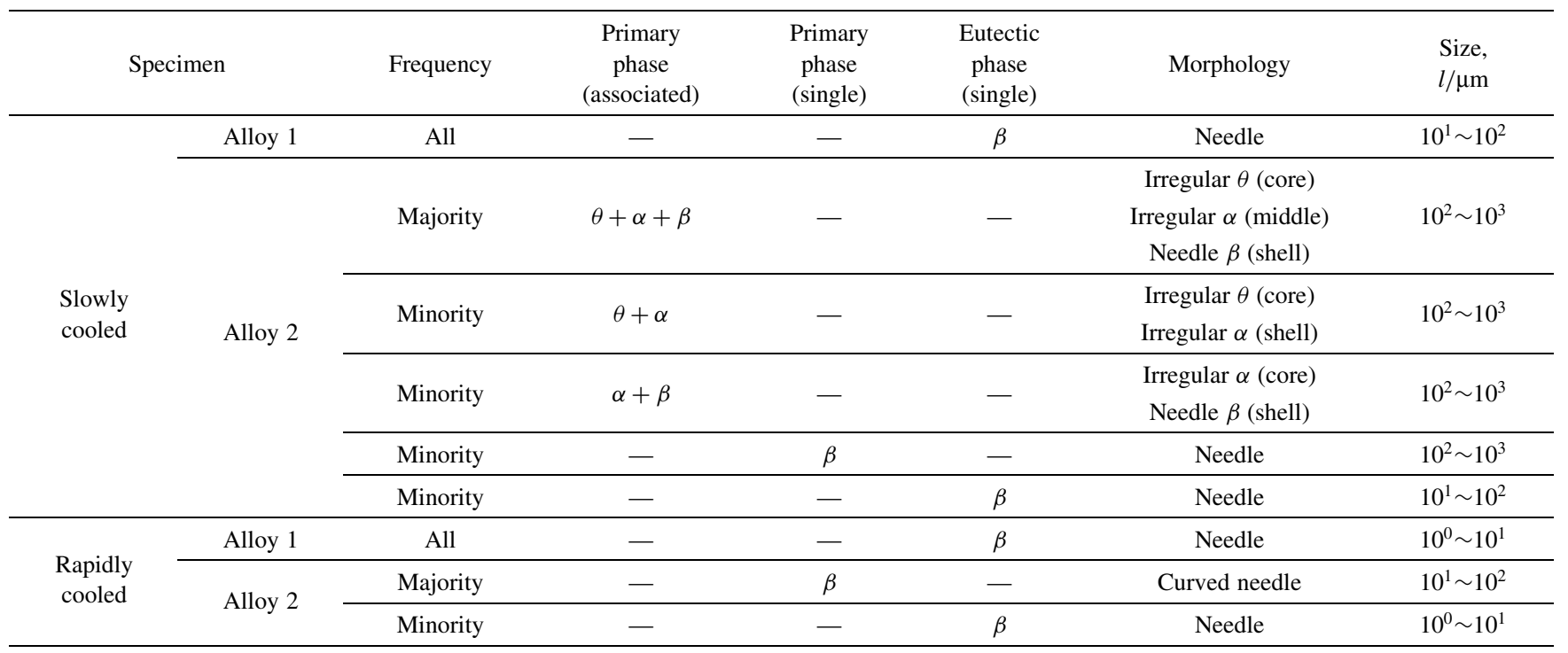

Here, the relative frequencies among all intermetallic compounds except the matrix were roughly expressed. In the case of needle-shaped intermetallic, the size is the lengthwise value.

Table 5 Average chemical compositions of intermetallic compounds observed in two different specimens of low and high Fe-containing hypoeutectic Al-Si alloys solidified under slowly-cooled conditions.

\begin{tabular}{cccccc}
\hline \multirow{2}{*}{ Specimen } & Phase & \multirow{2}{*}{$\begin{array}{c}\text { Number of } \\
\text { measurements }\end{array}$} & \multicolumn{2}{c}{ Chemical composition (mole\%) } \\
\cline { 4 - 6 } & & & $\mathrm{Al}$ & $\mathrm{Fe}$ & $\mathrm{Si}$ \\
\hline Alloy 1 & $\beta$ & 2 & 70.3 & 12.9 & 16.9 \\
\hline \multirow{2}{*}{ Alloy 2 } & $\alpha$ & 4 & 74.4 & 22.6 & 3.1 \\
& $\alpha$ & 14 & 72.3 & 17.5 & 10.2 \\
& $\beta$ & 7 & 67.7 & 14.8 & 17.5 \\
\hline
\end{tabular}

For the slowly-cooled alloy 2, the matrix microstructure was similar to that of Fig. 5(a), although a large number of coarse irregular-shaped precipitates were observed (Fig. 6(a)). An enlarged view (Fig. 6(b)) revealed a clear contrast within these precipitates. From the results of combined analyses of SEM(BSE) and EDS, as shown in Fig. 6(d) and Table 5, it was verified that the white core of the irregular-shaped precipitate was the $\theta$ phase, the bright gray middle shell enveloping the core was the $\alpha$ phase, and the dark gray final shell with a large number of needle plates was the $\beta$ phase. As shown in Fig. 6(c), the existing irregular-shaped precipitates were mostly the associated phases of $\theta+\alpha+\beta$ together with a small number of associated phases of either $\theta+\alpha$ or $\alpha+\beta$. A small amount of single $\beta$ phase not associated with $\theta$ or $\alpha$ phase was also found in Fig. 6(c). Among these $\beta$ phase needles with a length range of $10 \sim 1000 \mu \mathrm{m}$, fine eutectic $\beta$ phase needles with a length range of $10 \sim 100 \mu \mathrm{m}$ were observed in the interdendritic regions.

Figure 7 shows OM images of the rapidly-cooled low Fecontaining hypoeutectic Al-Si alloy (alloy 1). A fine dendritic primary $(\mathrm{Al})$ phase, together with very fine eutectic $(\mathrm{Al})$ and (Si) phases, was observed in Fig. 7(a). As shown in Fig. 7(b), a small amount of very fine needle-shaped eutectic $\beta$ phase with a length range of $1 \sim 10 \mu \mathrm{m}$ was present in the eutectic regions of the $(\mathrm{Al})$ and $(\mathrm{Si})$ phases.
Figures 8 and 9 show OM and SEM(BSE) images, respectively, of the rapidly-cooled high Fe-containing hypoeutectic Al-Si alloy (alloy 2). For this alloy, it was difficult to identify the existing phases, as shown in Fig. 8(a). This may be due to a large number of primary $\beta$ phases intersecting with the primary (Al) phase. As shown in Fig. 8(b), a large amount of primary $\beta$ phase with a length range of $10 \sim 100 \mu \mathrm{m}$ was predominantly observed in the entire microstructure. A small amount of eutectic $\beta$ phase with a length range of $1 \sim 10 \mu \mathrm{m}$ was also found locally in the eutectic region. Here, it should be mentioned that the general morphology of the coarse primary $\beta$ phases are more or less shaped in the form of curved rather than straight needles, as shown in Fig. 9.

\section{Discussion}

\subsection{Solidification path-dependent phase formation}

As shown in Table 3 and Fig. 3, among the twenty seven ternary invariant reactions of the Al-Si-Fe system, only five can form $\beta$ phase. For the Fe-containing hypoeutectic Al-Si alloys selected in this study, the formation of $\beta$ phase can occur by the $\mathrm{U}_{3}$ quasi-peritectic reaction and/or the $E_{1}$ eutectic reaction. In the cases of eutectic and hypereutectic Al-Si alloys, the $\beta$ phase can be formed by the $\mathrm{U}_{1}$ quasiperitectic, $\mathrm{U}_{3}$ quasi-peritectic, and/or $\mathrm{E}_{1}$ eutectic reactions and by the $\mathrm{P}_{2}$ peritectic, $\mathrm{U}_{4}$ quasi-peritectic, and/or $\mathrm{E}_{1}$ eutectic reactions, respectively. The $\mathrm{E}_{1}$ ternary eutectic reaction has the lowest reaction temperature $\left(579^{\circ} \mathrm{C}\right)$ among all ternary invariant reactions of the Al-Si-Fe system, and can occur as a common final ternary invariant reaction in all three types of Fe-containing Al-Si alloys.

For the slowly-cooled alloy 1 , the fine $\beta$ phases formed in the interdendritic region were a unique type of Fe-rich intermetallic compound observed in the final microstructure, as shown in Fig. 5(c). If the initial composition, which can form $\beta$ phase by the $\mathrm{E}_{1}$ ternary eutectic reaction exclusively, 

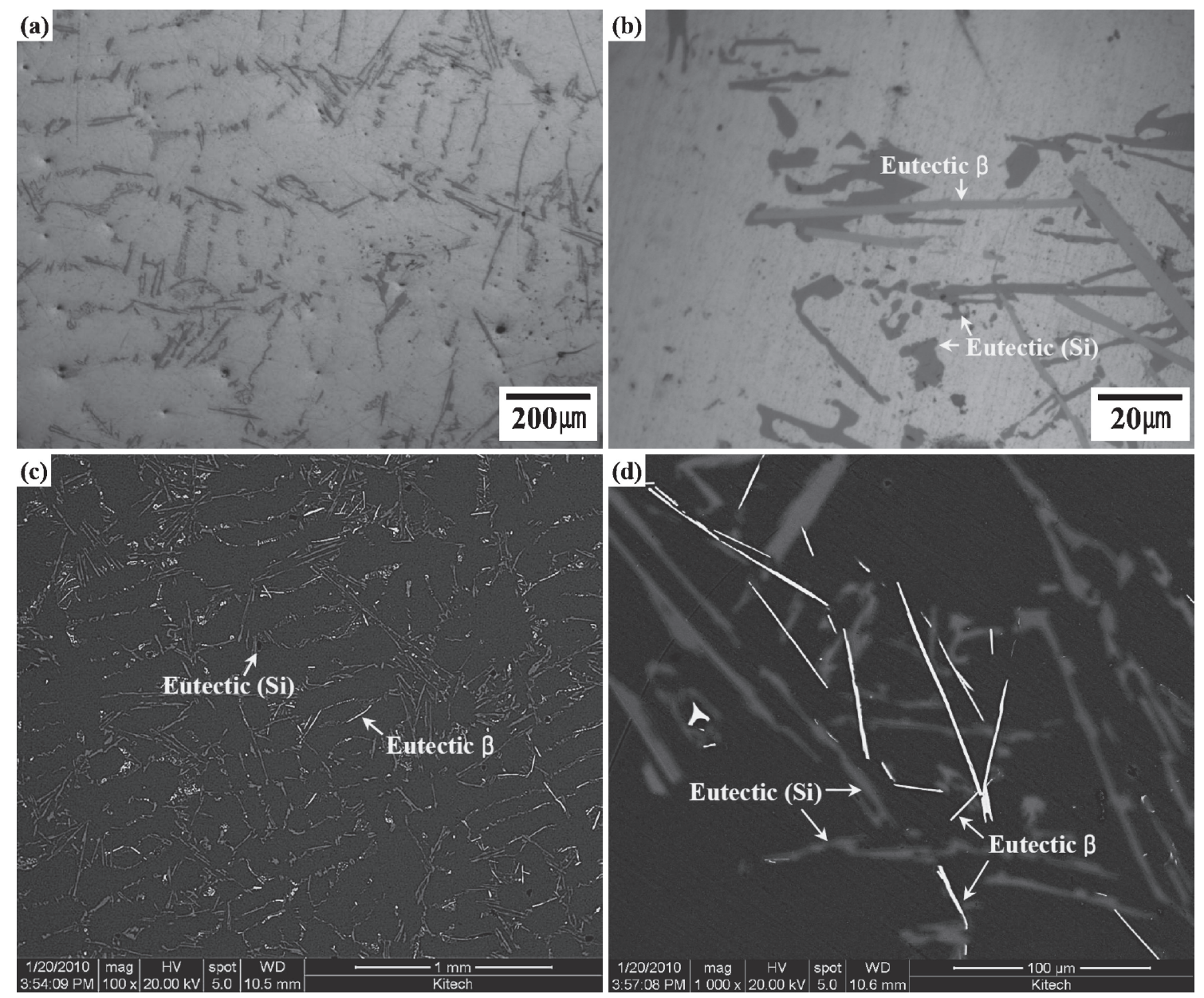

Fig. 5 Representative microstructural features of slowly-cooled alloy 1; (a) low magnification optical micrograph, (b) enlarged view of (a), (c) low magnification back-scattered scanning electron micrograph, and (d) enlarged view of (c).

is adopted in Fe-containing Al-Si alloys, the length of the $\beta$ phase can be minimized because of the low starting temperature for $\beta$ phase formation and growth constraint within the eutectic regions of the $(\mathrm{Al})$ and $(\mathrm{Si})$ phases. It has been well known that in Fe-containing Al-Si alloys with an initial composition of $\mathrm{Si}$ and $\mathrm{Fe}$ within the primary field of (Al), formation of the primary $\beta$ phase prior to the $\mathrm{E}_{1}$ ternary eutectic reaction can be decided by the critical Fe content $\left(\mathrm{Fe}_{\mathrm{CR}}\right),{ }^{9)}$ which is plotted by the dash-dot line in Fig. 3(a). If the initial composition within the primary field of $(\mathrm{Al})$ is above the $\mathrm{Fe}_{\mathrm{CR}}$ and the cooling rate is sufficiently slow, the liquid composition can move to the monovariant reaction line $\mathrm{U}_{3}-\mathrm{E}_{1}$ of $\mathrm{L} \rightarrow(\mathrm{Al})+\beta$ because of formation of the primary (Al) phase, and the primary $\beta$ phase can form as a result of the change in liquid composition. In the case of alloy 1 , the fine eutectic $\beta$ phase among various Fe-rich intermetallic compounds was only formed in the finally solidified part by the $E_{1}$ ternary eutectic reaction of $\mathrm{L} \rightarrow(\mathrm{Al})+(\mathrm{Si})+\beta$ because the initial composition was below $\mathrm{Fe}_{\mathrm{CR}}$.

There are three ternary invariant reactions that can form the $\alpha$ phase in the Al-Si-Fe system. For the Fe-containing hypoeutectic Al-Si alloys selected in this study, the formation of the $\alpha$ phase can occur by the $\mathrm{P}_{1}$ peritectic and/or $\mathrm{U}_{2}$ quasiperitectic reactions. For eutectic Al-Si alloys, the $\mathrm{U}_{1}$ quasiperitectic reaction is the only ternary invariant reaction that forms the $\alpha$ phase. The $\mathrm{P}_{1}$ ternary peritectic reaction has the highest reaction temperature $\left(751^{\circ} \mathrm{C}\right)$ among the three ternary invariant reactions mentioned above, and can be terminated by the consumption of either the $\theta$ or $\gamma$ phases.

For the slowly-cooled alloy 2 , the most dominant phase among the observed various intermetallic compounds was the $\alpha$ phase located at the $\theta / \beta$ interface, as shown in Figs. 6(c) and $6(\mathrm{~d})$. Figure 10 exhibits the first derivative of the cooling curve for the slowly-cooled alloy 2 . The peaks identified in Fig. 10 closely correspond to the invariant reactions of the solidification sequence, as was predicted thermodynamically in Fig. 4(b). In particular, prominent peaks corresponding to the formation reactions of the $\alpha$ phase such as the $\mathrm{P}_{1}-\mathrm{U}_{2}$ monovariant reaction of $\mathrm{L} \rightarrow \theta+\alpha$ (the broad peak with a temperature range of $630 \sim 670^{\circ} \mathrm{C}$ ) and the $\mathrm{U}_{2}$ quasi-peritectic reaction of $\mathrm{L}+\theta \rightarrow(\mathrm{Al})+\alpha$ were detected (Fig. 10). It is verified that the peak of the $\mathrm{U}_{2}$ quasi-peritectic reaction overlaps considerably with that of the $U_{1}$ quasiperitectic reaction given the small difference between the two reaction temperatures. It is expected that the $\alpha$ phase first begins to form by the $\mathrm{P}_{1}$ peritectic reaction. However, it was difficult to identify any noticeable peak corresponding to this reaction in the high temperature region (not shown in Fig. 10). This is presumably because the $\mathrm{P}_{1}$ ternary peritectic reaction is quickly terminated, given that the amount of the $\gamma$ 

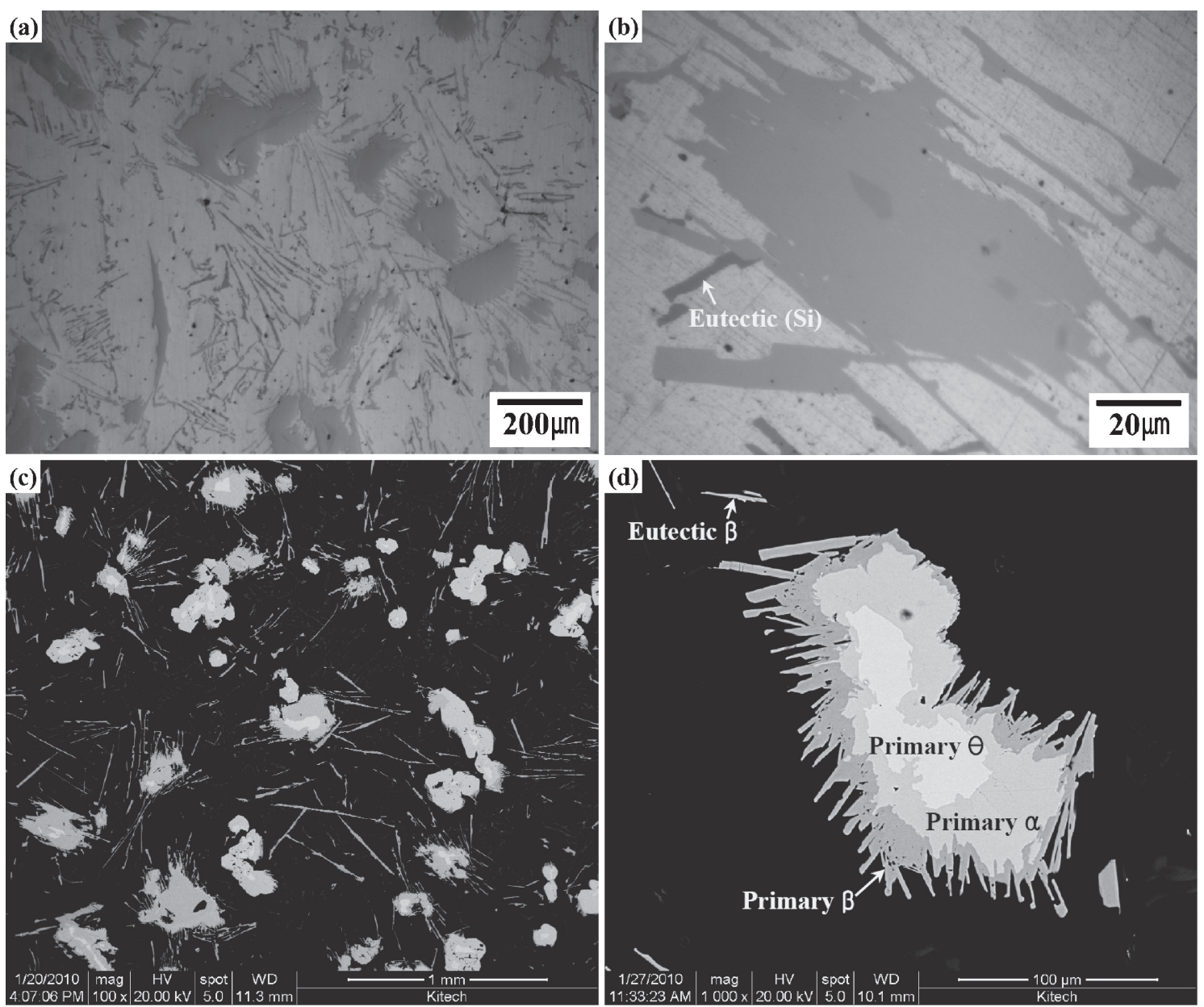

Fig. 6 Representative microstructural features of slowly-cooled alloy 2; (a) low magnification optical micrograph, (b) enlarged view of (a), (c) low magnification back-scattered scanning electron micrograph, and (d) enlarged view of (c).
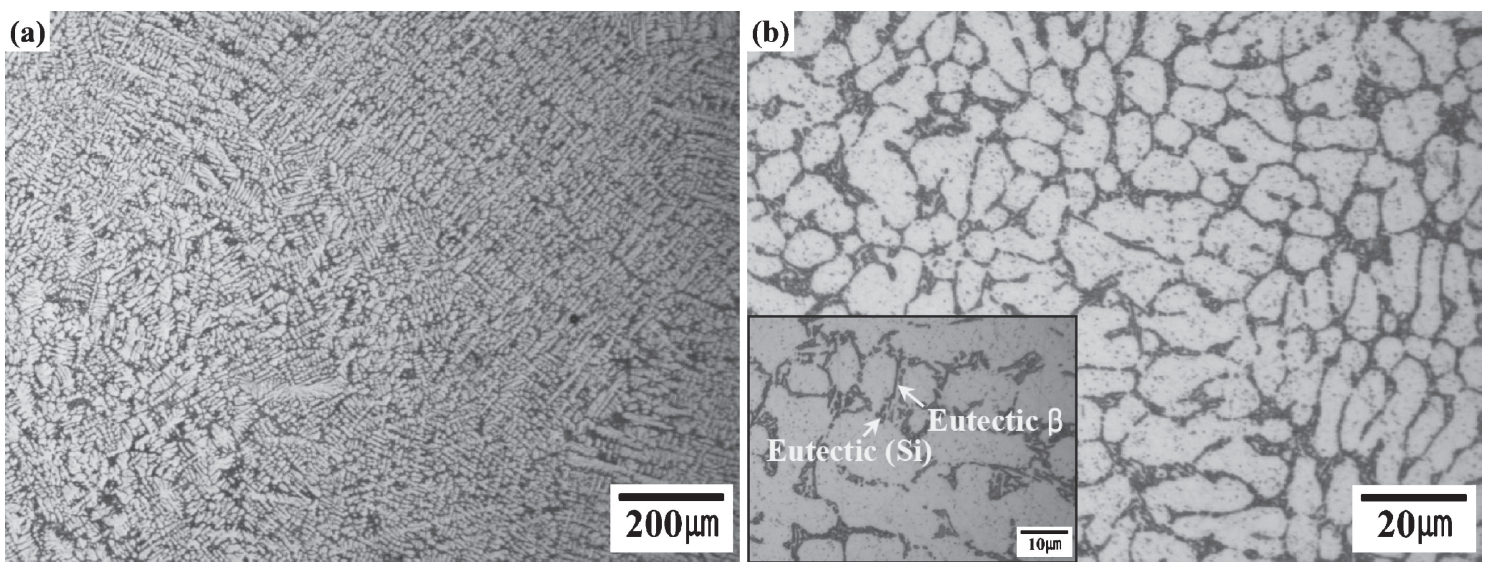

Fig. 7 Representative microstructural features of rapidly-cooled alloy 1; (a) low magnification optical micrograph and (b) enlarged view of (a). Inset in (b) shows two-times magnified view of (b) to distinguish the eutectic $\beta$ phase from the eutectic (Si) phase.

phase, which is necessary to advance the $\mathrm{P}_{1}$ reaction, is very small. In the case of the slowly-cooled alloy 2 , the large amount of the $\alpha$ phase predominantly formed because of the high starting temperature for $\alpha$ phase formation corresponds to point $\mathrm{P}_{1}\left(751^{\circ} \mathrm{C}\right)$, and the wide formation temperature range corresponds to line $\mathrm{P}_{1}-\mathrm{U}_{2}-\mathrm{U}_{3}\left(612 \sim 751^{\circ} \mathrm{C}\right)$.

The coarse irregular-shaped associated phases of $\theta+\alpha+$ $\beta$ were predominantly observed in the slowly-cooled alloy 2 , as shown in Fig. 6(c). The irregular-shaped $\alpha$ phase enveloping the $\theta$ phase is a product of the $\mathrm{P}_{1}$ peritectic reaction of $\mathrm{L}+\theta+\gamma \rightarrow \alpha$ and/or the $\mathrm{U}_{2}$ quasi-peritectic reaction of $\mathrm{L}+\theta \rightarrow(\mathrm{Al})+\alpha$. The needle-shaped $\beta$ phase located at the $\alpha$ /liquid interface is a product of the $\mathrm{U}_{3}$ quasi-peritectic reaction of $\mathrm{L}+\alpha \rightarrow(\mathrm{Al})+\beta$. For the formation of primary $\beta$ phase in the event that a large amount of primary $\theta$ and $\alpha$ phases have already formed, it is thought that the heteroge- 

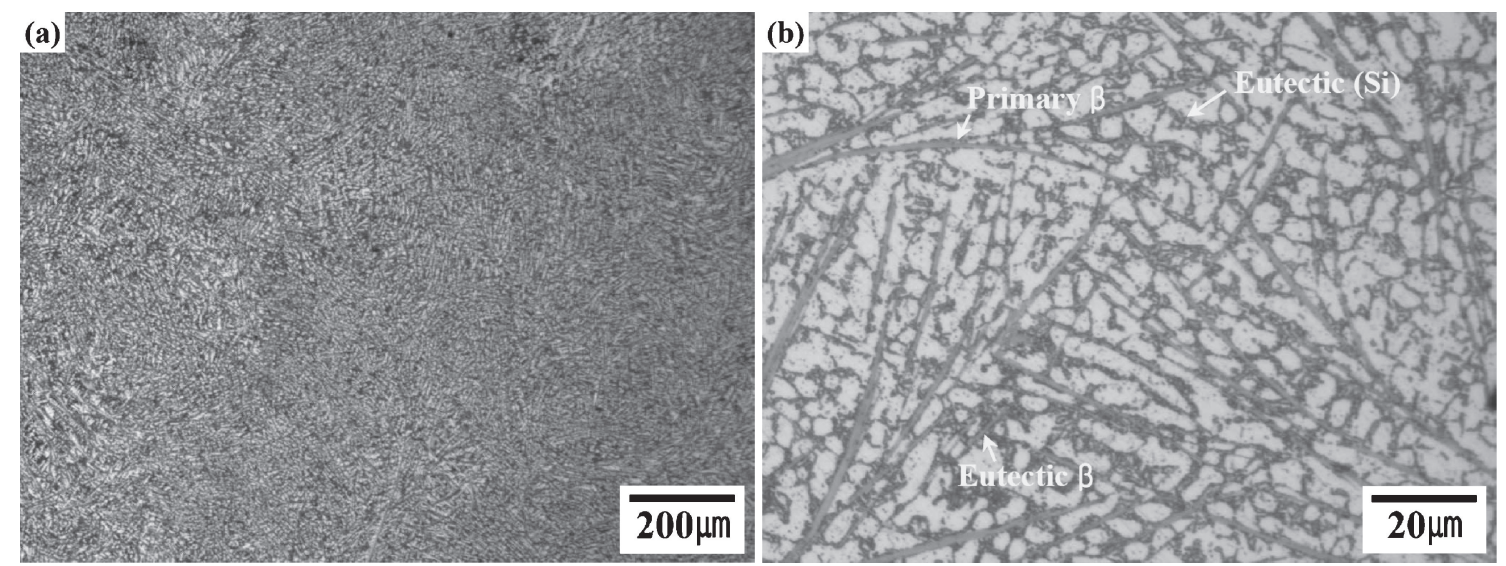

Fig. 8 Representative microstructural features of rapidly-cooled alloy 2; (a) low magnification optical micrograph and (b) enlarged view of (a).

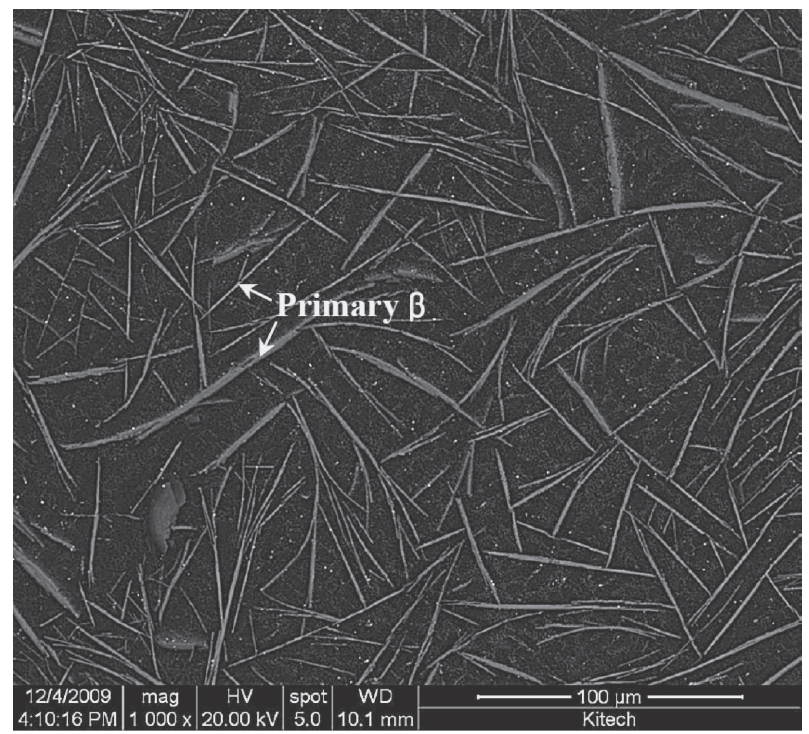

Fig. 9 Back-scattered scanning electron micrograph of rapidly-cooled alloy 2 .

neous nucleation of $\beta$ phase at the $\alpha /$ liquid interface is more dominant than the homogeneous nucleation in the liquid by either the reaction of $\mathrm{L} \rightarrow(\mathrm{Al})+\beta$ or the reaction of $\mathrm{L} \rightarrow \beta$. Regarding the solid phase consumption by a quasiperitectic reaction, the detected primary $\theta$ and $\alpha$ phases were the results of incomplete $\mathrm{U}_{2}$ and $\mathrm{U}_{3}$ quasi-peritectic reactions, respectively.

Under the rapid cooling condition, a change of liquid composition hardly occurs because the formation of primary solid phase and the diffusion of solute atoms are inhibited. In this case, it is appropriate for the solidification reaction to be predicted from the equilibrium phase fraction than from the liquidus projection. Figure 11 shows the calculated equilibrium phase fractions of the two hypoeutectic Al-Si alloys selected in this study. For the rapidly-cooled alloy 1, a very fine $\beta$ phase, together with eutectic (Al) and ( $\mathrm{Si}$ ) phases, was observed in the finally solidified part because the initial composition was below $\mathrm{Fe}_{\mathrm{CR}}$, as in the slowly-cooled case (inset of Fig. 7(b)). It is well known that a supersaturated (Al) solid solution containing up to $10 \sim 16$ mass $\%$ Si can be formed under ultra-high cooling conditions. ${ }^{35)}$ It was found

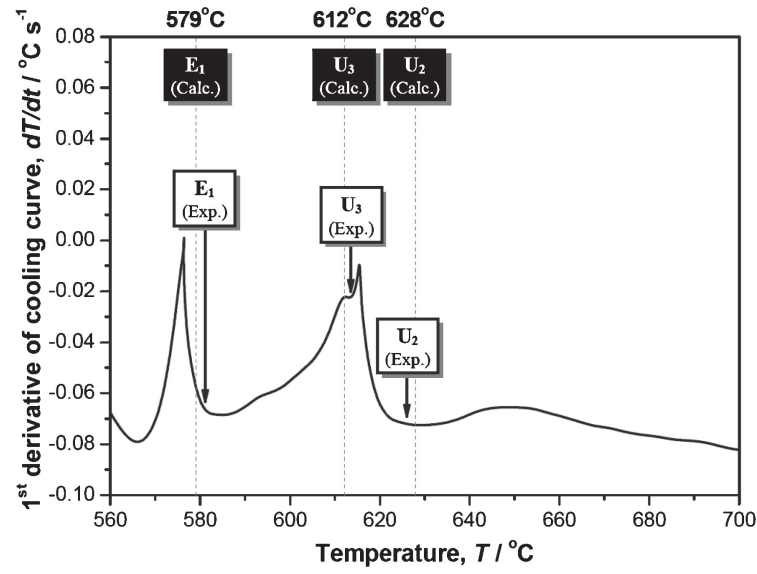

Fig. 10 First derivative of the cooling curve for slowly-cooled alloy 2.

that the large numbers of nano-scale particles present within the primary (Al) phase (Fig. 7(b)) consisted of supersaturated $\mathrm{Si}$ and $\mathrm{Fe}$ atoms. Therefore, it is predicted that there is little change in the liquid composition by the formation of the primary ( $\mathrm{Al}$ ) phase above the $\mathrm{E}_{1}$ eutectic reaction temperature. In such a case, it is predicted that the maximum amount of the eutectic $\beta$ phase, which is dependent on the initial composition, is about 0.8 mass\% (Fig. 11(a)). However, it is thought that the actual amount of the eutectic $\beta$ phase is smaller than that of the equilibrium condition because of the increased formation of supersaturated $(\mathrm{Al})$ phase.

For the rapidly-cooled alloy 2, a curved needle-shaped primary $\beta$ phase was predominantly observed in the final microstructure, as shown in Fig. 9. In this case, it is predicted that the primary $\beta$ phase is mainly formed together with the primary $(\mathrm{Al})$ phase by the reaction of $\mathrm{L} \rightarrow(\mathrm{Al})+\beta$ $\left(579 \sim 612^{\circ} \mathrm{C}\right)$, as shown in Fig. 11(b). It is noted that there is no change of liquidus composition prior to the reaction given the absence of the primary $\theta$ and $\alpha$ phases, as identified in Fig. 9. It is thought that the primary $\beta$ phase grows straight along the lengthwise direction in the early stages of the reaction. However, the growth direction is affected by the supply of $\mathrm{Si}$ and $\mathrm{Fe}$ atoms during bumping into the dendritic primary ( $\mathrm{Al}$ ) phase, leading to the formation of a curved needle-shaped $\beta$ phase. 

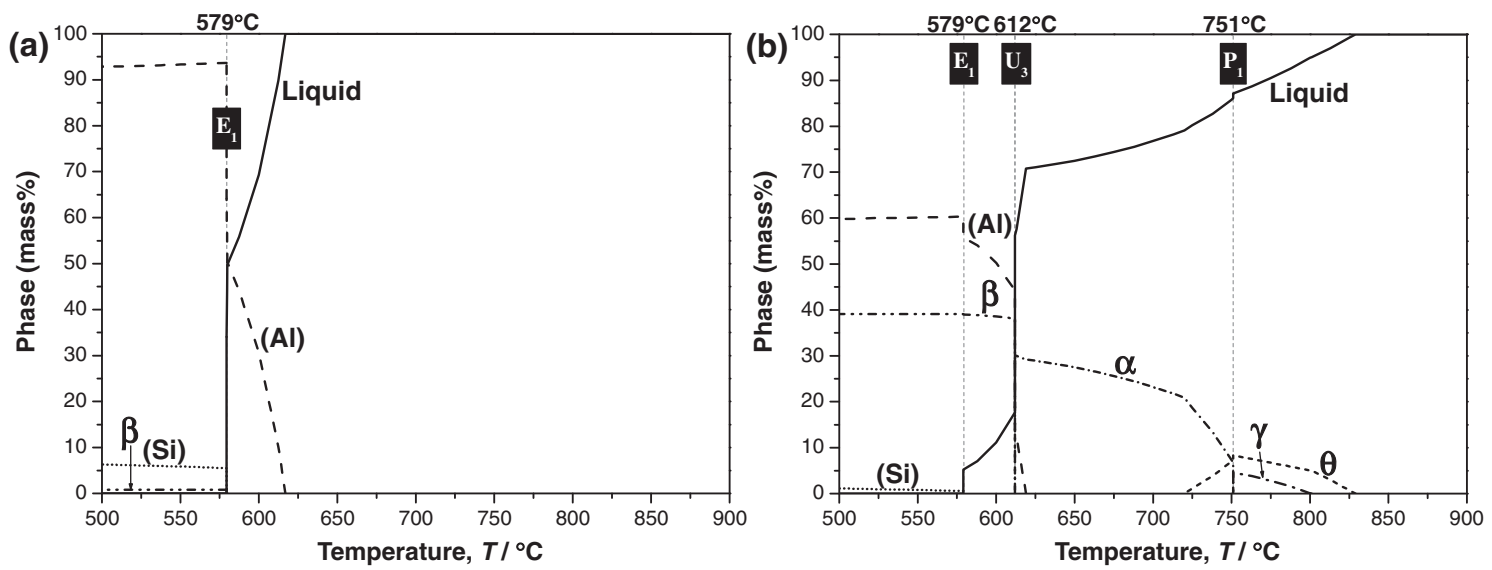

Fig. 11 Calculated equilibrium phase fractions; (a) alloy 1 and (b) alloy 2.

\subsection{Effect of Fe content on $\boldsymbol{\beta}$ phase formation}

For the two slowly-cooled alloys, with increasing $\mathrm{Fe}$ content above 10 mass $\%$, the primary $\beta$ phase formed by the $\mathrm{U}_{3}$ quasi-peritectic reaction of $\mathrm{L}+\alpha \rightarrow(\mathrm{Al})+\beta\left(612^{\circ} \mathrm{C}\right)$ was more dominant than the eutectic $\beta$ phase formed by the $\mathrm{E}_{1}$ eutectic reaction of $\mathrm{L} \rightarrow(\mathrm{Al})+(\mathrm{Si})+\beta\left(579^{\circ} \mathrm{C}\right)$. For the two rapidly-cooled alloys, with increasing Fe content, the primary $\beta$ phase formed by the reaction of $\mathrm{L} \rightarrow(\mathrm{Al})+\beta$ $\left(579 \sim 612^{\circ} \mathrm{C}\right)$ was more dominant than the eutectic $\beta$ phase. In the both cases of the slowly- and rapidly-cooled hypereutectic Al-Si alloys, the length of the $\beta$ phase increased by about an order of magnitude. It is verified that increasing the Fe content promotes increases in the amount and length of the $\beta$ phase. This is because the supply of $\mathrm{Fe}$ atoms for $\beta$ phase growth is facilitated by increases in the $\beta$ phase formation temperature (related to the diffusivity of Fe atoms) and the solute Fe concentration in the liquid (related to the jump frequency of Fe atoms).

\subsection{Effect of cooling rate on $\boldsymbol{\beta}$ phase formation}

In both cases of alloy 1 and 2 , by increasing the cooling rate to a level of $250 \sim 300^{\circ} \mathrm{C} / \mathrm{s}$, the length of the $\beta$ phase decreased by about an order of magnitude. It is thought that increasing the cooling rate inhibits the formation of the coarse $\beta$ phase because of an insufficient exhaustion of incubation time for nucleation and a shortage of time for lengthwise growth. For alloy 2 , the amount of the $\beta$ phase increased with increasing cooling rate. This is because the high cooling rate inhibited formation of the $\theta$ and $\alpha$ phases. It may be argued that the amount and length of the $\beta$ phase in alloy 2 cannot be completely controlled by high cooling rates of $250 \sim 300^{\circ} \mathrm{C} / \mathrm{s}$.

\section{Conclusions}

Thermodynamic calculations were carried out to predict the solidification sequences and formation behaviors of the $\beta$ phase in Fe-containing hypoeutectic Al-Si alloys. These predictions were verified by appropriate experimentation. The main findings are as follows.

(1) For slowly-cooled high Fe-containing hypoeutectic Al-Si alloys, the needle-shaped primary $\beta$ phase was predominantly formed at the $\alpha$ /liquid interface by the quasi-peritectic reaction of $\mathrm{L}+\alpha \rightarrow(\mathrm{Al})+\beta$ $\left(612^{\circ} \mathrm{C}\right)$. As a result, an irregular-shaped precipitate was the associated phase of $\theta+\alpha+\beta$ in the final microstructure.

(2) For rapidly-cooled high Fe-containing hypoeutectic Al$\mathrm{Si}$ alloys, the curved needle-shaped primary $\beta$ phase with a length range of $10^{1} \sim 10^{2} \mu \mathrm{m}$ was predominantly formed by the reaction of $\mathrm{L} \rightarrow(\mathrm{Al})+\beta\left(579 \sim 612^{\circ} \mathrm{C}\right)$ under conditions of growth constraint.

(3) By increasing the Fe content above 10 mass $\%$, the length of the $\beta$ phase increased by about an order of magnitude.

(4) By increasing the cooling rate to a level of $250 \sim$ $300^{\circ} \mathrm{C} / \mathrm{s}$, the length of the $\beta$ phase decreased by about an order of magnitude.

(5) For high Fe-containing hypoeutectic Al-Si alloys, the amount of the $\beta$ phase increased somewhat by rapid cooling.

\section{REFERENCES}

1) J. E. Gruzleski and B. M. Closet: The Treatment of Liquid AluminumSilicon Alloys, (American Foundrymen's Society, Des Plaines, 1990).

2) I. J. Polmear: Light Alloys, (Edward Arnold, London, 1989).

3) N. Saheb, T. Laoui, A. R. Daud, M. Harun, S. Radiman and R. Yahaya: Wear 249 (2001) 656-662.

4) H. Ye: J. Mater. Eng. Perform. 12 (2003) 288-297.

5) S. P. Nikanorov, M. P. Volkov, V. N. Gurin, Y. A. Burenkov, L. I. Derkachenko, B. K. Kardashev, L. L. Regel and W. R. Wilcox: Mater. Sci. Eng. A 390 (2005) 63-69.

6) W. Eidhed: J. Mater. Sci. Technol. 24 (2008) 45-47.

7) T. A. Burns: The Foseco Foundryman's Handbook, (Pergamon, Oxford, 1986).

8) N. A. Belov, A. A. Aksenov and D. G. Eskin: Iron in Aluminum Alloys: Impurity and Alloying Element, (Taylor \& Francis, London, 2002).

9) J. A. Taylor: Casting Concepts, 35th Australian Foundry Institute National Conference, ed. by J. Couzner, (Autralian Foundry Institute, Adelaide, 2004) pp. 148-157.

10) L. F. Mondolfo: Aluminum Alloys: Structure and Properties, (Butterworths, London, 1976).

11) A. M. Samuel, F. H. Samuel, C. Villeneuve, H. W. Doty and S. Valtiera: Int. J. Cast Met. Res. 14 (2001) 97-120.

12) J. Z. Yi, Y. X. Gao, P. D. Lee and T. C. Lindley: Mater. Sci. Eng. A 386 (2004) 396-407.

13) S. Seifeddine, S. Jhansson and I. L. Svensson: Mater. Sci. Eng. A 490 (2008) 385-390.

14) X. Ma, A. M. Samuel, F. H. Samuel, H. W. Doty and S. Valtierra: 
Mater. Sci. Eng. A 490 (2008) 36-51.

15) S. G. Shabestari: Mater. Sci. Eng. A 383 (2004) 289-298.

16) A. Couture: AFS Inter. Cast Met. J. 6 (1981) 9-17.

17) M. R. Ghomashchi: Z. Metallk. 78 (1987) 784-787.

18) S. Shankar and D. Apelian: Metall. Mater. Trans. B 33 (2002) 465-476.

19) H. P. Takeda and K. Mutuzaki: Tetsu-to-Hagané 26 (1940) 335-361.

20) S. P. Gupta: Mater. Charact. 49 (2003) 269-291.

21) S. T. Maitra and S. P. Gupta: Mater. Charact. 49 (2003) 293-311.

22) F. Bosselet, S. Pontevichi, M. Perronet and J. C. Viala: J. Phys. IV France 122 (2004) 41-46.

23) S. Pontevichi, F. Bosselet, O. Dezellus, M. Perronet, D. Rouby and J. C. Viala: J. Phys. IV France 122 (2004) 75-80.

24) S. Pontevichi, F. Bosselet, F. Barbeau, M. Perronet and J. C. Viala: J. Phase Equilib. Diffus. 25 (2004) 528-537.

25) S. Pontevichi, F. Bosselet, M. Perronet and J. C. Viala: J. Phys. IV France 113 (2004) 81-84.

26) N. Krendelsberger, F. Weitzer and J. C. Schuster: Metall. Mater. Trans.
A 38 (2007) 1681-1691.

27) Z. K. Liu and Y. A. Chang: Metall. Mater. Trans. A 30 (1999) 10811095.

28) Y. Du, J. C. Schuster, Z. K. Liu, R. Hu, P. Nash, W. Sun, W. Zhang, J. Wang, L. Zhang, C. Tang, Z. Zhu, S. Liu, Y. Ouyang, W. Zhang and N. Kredelsberger: Intermetallics 16 (2008) 554-570.

29) G. Shao: Intermetallics 12 (2004) 655-664.

30) C. Guo, Z. Du, C. Li, B. Zhang and M. Tao: Calphad 32 (2008) 637649.

31) M. H. G. Jacobs and R. S. Fetzer: Calphad 33 (2009) 170-178.

32) E. H. Dix Jr. and A. C. Heath Jr.: Trans. AIME, Inst. Met. Div. (1928) pp. 164-197.

33) A. G. C. Gwyer and H. W. L. Phillips: J. Inst. Met. 38 (1927) 44-83.

34) D. Munson: J. Inst. Met. 95 (1967) 217-219.

35) J. E. Hatch: Aluminum: Properties and Physical Metallurgy, (ASM, Metals Park, Ohio, 1984). 